\title{
PROPOSTA DE IMPLEMENTAÇÃO DA ESTRATÉGIA DE INTRODUÇÃO DO INBOUND MARKETING: ESTUDO DE CASO NA EMPRESA K MAIA DE SOUZA ASSESSORIA CONTÁBIL
}

\section{ARTIGO ORIGINAL}

SILVA FILHO, Mensala Cândido da ${ }^{1}$, GARCIA, Bruna Rafaela Schneider Pereira ${ }^{2}$, ALMEIDA, Victor da Silva ${ }^{3}$, LEITE, Ygor Geann dos Santos ${ }^{4}$, ROBERTO, José Carlos Alves 5

SILVA FILHO, Mensala Cândido da. Et al. Proposta de implementação da estratégia de introdução do inbound marketing: estudo de caso na empresa $\mathrm{K}$ Maia de Souza Assessoria Contábil. Revista Científica Multidisciplinar Núcleo do Conhecimento. Ano. 06, Ed. 11, Vol. 05, pp. 28-47. Novembro 2021. ISSN: 24480959, Link de acesso:

https://www.nucleodoconhecimento.com.br/administracao/introducao-do-inbound, DOI: 10.32749/nucleodoconhecimento.com.br/administracao/introducao-do-inbound

\section{RESUMO}

Este artigo tem por intuito propor aperfeiçoamentos para a área de marketing da organização K Maia de Souza Assessoria Contábil, que fica localizada na cidade de Manaus, Amazonas. De acordo com pesquisas realizadas dentro da empresa, observou-se que as atividades relativas à área de marketing se destacaram como as mais críticas, por expor os pontos fracos que necessitam de melhorias, sendo necessária a introdução de estratégias de Marketing. Considerando os problemas

\footnotetext{
${ }^{1}$ Graduando do curso de Administração.

${ }^{2}$ Graduanda do curso de Administração.

${ }^{3}$ Coorientador. Mestre em Engenharia de Processos. Pós-Graduando em Neuropsicopedagogia Institucional. Especialista em Gestão Estratégica de RH. Graduado em Administração e Pedagogia.

${ }^{4}$ Coorientador. Mestre em Ciência e Engenharia de Materiais. Especialista em Engenharia da Qualidade e Seis Sigma. Graduado em Tecnologia em Gestão da Qualidade.

${ }^{5}$ Orientador. Mestre em Engenharia de produção. Especialista Logística empresarial. Graduado em Administração com Ênfase em Marketing.
}

RC: 100851

Disponível em: https://www.nucleodoconhecimento.com.br/administracao/introducaodo-inbound 
identificados no diagnóstico organizacional, optou-se por construir o seguinte problema de pesquisa: como o inbound marketing pode beneficiar as microempresas? Com isso, o objetivo foi o de introduzir uma ferramenta que visa mudar a percepção dos clientes, fazendo uso, para isso, de conteúdos relevantes, o que implica melhorar os procedimentos de busca da empresa, blogs e redes sociais. O inbound é uma área do marketing que foca em atrair, converter e encantar o cliente. A metodologia utilizada propõe um estudo de caso, configurando-se como uma pesquisa aplicada. Os resultados verificados no estudo foram satisfatórios, visto que as propostas interventivas construídas direcionam a empresa a uma nova postura em relação às estratégias de marketing. Utilizou-se o 5W2H como instrumento para gestão da introdução das melhorias, especificamente o inbound marketing. O estudo construiu uma trilha que possibilita a organização e reconfiguração dos meios de busca de mecanismos que atraem a atenção do cliente. A empresa que pretende se tornar tecnológica deve pleitear maiores fatias de mercado no nicho no qual está inserida. Nesse sentido, este artigo pretende se tornar referencial para futuras pesquisas sobre o tema.

Palavras-chave: Marketing, Empresa, Clientes, Relacionamento, Captação.

\section{INTRODUÇÃO}

Este artigo propõe um estudo de caso relacionado à empresa $\mathrm{K}$ Maia de Sousa Assessoria Contábil. Tem-se como objetivo reconhecer os transtornos causados pela falta de conhecimento na área de marketing e como esses repercutem dentro da organização. Visa-se orientar todos aqueles que almejam implantar a ferramenta Inbound Marketing para solucionar um problema. Ao observar o contexto da corporação, notou-se que, por falta de investimento e conhecimento em marketing, a empresa encontrava-se com problemas relacionados à retenção e fidelização de seus clientes. Amparando-se nos problemas identificados no diagnóstico organizacional que remetem ao baixo envolvimento com relação aos assuntos relativos aos Marketing, construiu-se o seguinte problema de pesquisa: como o inbound marketing pode beneficiar as microempresas? O objetivo da implementação

RC: 100851

Disponível em: https://www.nucleodoconhecimento.com.br/administracao/introducaodo-inbound 
do inbound marketing é fazer com que seus clientes sejam atraídos e fiquem encantados com a empresa, convertendo pessoas em clientes. Para isso, torna-se essencial a otimização dos sites, gerando conteúdos relevantes.

Para isto, é necessária a utilização da estratégia $5 \mathrm{~W} 2 \mathrm{H}$. Este tipo de estratégia de marketing é de suma importância para o crescimento de uma empresa, pois visa à necessidade de crescimento de vendas, tanto pela internet ou por meio de sua forma física, cujo objetivo é reter e fidelizar novos clientes para a empresa. Estratégias de marketing nos dias atuais são necessárias para que haja facilidade para a empresa ao manusear a sua rede de contatos, sobretudo com o aumento da concorrência em diferentes nichos, visando à facilidade de se tornar uma empresa exemplo no seu meio de atuação local, transformando-se em um negócio visionário. O marketing digital é necessário em qualquer cenário e para qualquer empresa nos dias atuais, o que demonstra a importância da ferramenta para o fortalecimento da relação entre a empresa e o consumidor. Também é uma forma de fomentar a confiança na relação entre o consumidor e empresa que se apresenta. Isso dá ênfase e destaque para a empresa que deseja uma performance melhor que a concorrência.

Para que tudo isso se torne fato, é necessário a busca pelo público-alvo apropriado, isto é, para que haja um alcance amplo de novos clientes com potencial de fidelização. $O$ inbound, nesse contexto, tem a necessidade de fomentar a fidelidade do consumidor, trazendo-o para perto. A proposta apresentada à empresa diz respeito à incorporação do inbound marketing como uma ferramenta para obtenção de lucros e novos clientes para o negócio. Busca-se melhorar a qualidade do serviço que a empresa produz, transformando, nesse processo, o ambiente em um local mais novo e tecnológico, pois, hoje em dia, isto é o diferencial em qualquer lugar. Acredita-se que com a implantação dos métodos que serão utilizados na pesquisa, esta, por sua vez, será um exemplo para outras organizações. Os resultados esperados são a melhora da comunicação entre os funcionários e os seus clientes, bem como espera-se a obtenção dos melhores métodos que permitem reter mais lucros. O principal resultado almejado é tornar a empresa tecnológica.

RC: 100851

Disponível em: https://www.nucleodoconhecimento.com.br/administracao/introducaodo-inbound 


\section{FUNDAMENTAÇÃO TEÓRICA}

O trabalho realizado demonstra como a aplicação do Inbound Marketing acrescenta valor para a organização. Identificou-se que os clientes sentiram-se satisfeitos após a aplicação deste estudo, gerando, para a empresa, subsídios que permitem que esta tenha capacidade para entender o mundo do marketing. Hoje em dia não basta se tornar uma organização, é preciso que a sua produção diária gere produtos que as pessoas sintam vontade de adquirir. Inbound Marketing é uma ferramenta estratégica para atrair pessoas e convertê-las em clientes. Observou-se que esta ferramenta entrega valor e conquista a confiança do cliente, fazendo-se com que estes tenham um interesse no serviço oferecido pela organização. Com isso, é importante ressaltar que se trata de uma pesquisa voltada à área do marketing.

\subsection{INBOUND MARKETING}

O Inbound Marketing busca a inovação em qualquer segmento, seja ele aplicado em indústrias ou até mesmo em pequenos negócios. As instituições buscam pelo aperfeiçoamento dos seus produtos e serviços para que se tornem mais acessíveis para todos os públicos. Com o aumento da demanda de pedidos por meios digitais, o consumo por meio dessas plataformas tomou espaço no mercado, tornando-se um campo de maior liquidez para as empresas, tornando a vida e o tempo do cliente mais fácil e eficaz, respectivamente. Como todo processo, é necessário buscar alguma forma de melhorar as tomadas de decisões de cada empresa. De acordo com Calil (2019), o marketing fomenta o acesso às diversas informações e possibilidades. Cabe ao gestor pensar em maneiras diferentes de aplicar tais dados para entender o que cada cliente precisa, ou seja, o público-alvo.

Para Camacho (2019), entende-se que o Inbound Marketing é um dos métodos mais eficazes para obter resultados nas mídias digitais de maneira rápida e dinâmica. Com esse método, a maioria das empresas podem alavancar suas vendas. Entende-se que o marketing é um dos novos fatores a serem estudados e implantados nas empresas. A partir de estudos feitos nos anos atuais, tem-se

RC: 100851

Disponível em: https://www.nucleodoconhecimento.com.br/administracao/introducaodo-inbound 
detectado, com base na literatura atualizada, que as empresas que usam o marketing como ferramenta para captação de novos métodos para alavancar de alguma forma o seu negócio, ou melhorar a visão geral da empresa, com base nos seus dados relacionados, têm tido um desempenho superior. De acordo com Guimarães (2018), o marketing e o conhecimento são de uso estratégico, sendo eles fatores dominantes para o sucesso de qualquer negócio.

\subsection{ACOMPANHAR OS RESULTADOS}

Os resultados de qualquer empresa demonstram o nível de crescimento ou queda da produção e dos seus serviços. Entende-se que fazer o acompanhamento, desde a rotina dos colaboradores até a linha de produção de cada máquina, é importante para monitorar os gastos de cada setor, para, assim, melhorar o faturamento da instituição. Na empresa K Maia de Souza, os funcionários precisam de um acompanhamento dos seus resultados para que a empresa consiga ter um controle maior dos setores com os melhores e piores desempenhos. Após detalhar todo o processo para os gestores da empresa, é necessário que a prática seja feita de forma eficiente para que os resultados sejam positivos. De acordo com Francischini (2017), os indicadores da empresa precisam apontar resultados. Caso os tempos de oscilação dos indicadores aumentem gradativamente e ninguém tome providências, o melhor seria não ter indicadores.

Para Grove (2020), o resultado do desempenho dos gestores ou da empresa é o resultado da performance da organização como um todo em seu dia a dia, isto é, são atividades da rotina que demonstram tal resultado, ou seja, os colaboradores da instituição, sob as supervisões e influências, garantem este resultado. Por meio da alavancagem gerencial, mensura-se o impacto dos gestores, avaliando-se se eles têm aumentado o output da equipe. Os acompanhamentos dos resultados da empresa, na maioria das vezes, precisam ser ajustados e monitorados diariamente, por motivo simples. A empresa precisa que a sua produção aumente diariamente, o que implica atingir as metas estabelecidas pelos seus gestores e sócios. Uma instituição sem acompanhamento não consegue de nenhuma maneira demonstrar

RC: 100851

Disponível em: https://www.nucleodoconhecimento.com.br/administracao/introducaodo-inbound 
para os seus empregados o que deve ser produzido e conquistado por cada um deles.

Um dos motivos para melhorar o desempenho diz respeito às recompensas oferecidas a cada um dos colaboradores, pois são eles que fazem com que os resultados da empresa sejam alcançados. Se a empresa colocar em prática esses tipos de técnicas, isto nunca seria um desperdício, mas lucro, uma vez que os gestores terão investido nos seus funcionários, porém, sem desviar dos fins lucrativos no seu resultado final. Todavia, o resultado principal esperado é a obtenção de mais agilidade no dia a dia organizacional. Os resultados, após serem acompanhados, passam a ser, na maioria das vezes, positivos para as empresas e seus gestores.

\subsection{ESTRUTURAR OS LEADS}

Destaca-se que os leads das empresas são de suma importância para os colaboradores e gestores da empresa. A partir deles os contatos dos possíveis consumidores estarão dispostos à organização. É um mecanismo para chamar atenção dos seus clientes, pois, com a estratégia, tornam mais atraentes os seus serviços, demonstrando qual o tipo de perfil no qual os consumidores dos produtos ou serviços se encaixam. Os produtos e/ou serviços devem levar em consideração este público-alvo. Os leads da empresa são criados para saber qual a intenção dos seus clientes e fazer com que tenham fácil acesso nas suas buscas. Com isso, o público-alvo da empresa começa se tornar maior, pois, com os dados dos clientes e tendo em mãos os tipos de buscas feitas por eles, a empresa começa a ter um embasamento maior acerca dos seus clientes e suas procuras.

Para Silva e Galegale (2018), existem, hoje, três formas de captura de leads: 1- por meio de e-mail enviado dos colaboradores da empresa que estiveram em contato com os clientes; 2- via telefone, cujos clientes das empresas são contatados por meio de um atendimento direto com o funcionário pelo telefone divulgado; e 3- por plataformas online ou eventos, como feiras, campanhas, site, sendo que nelas são 
coletados os dados também por meio dos formulários. De acordo com Conversion (2015), no setor de marketing, o "lead" é definido como um cliente que demonstra interesse em produtos ou serviços que estejam à venda, fornecendo, assim, os seus dados pessoais e contatos para que a empresa consiga unificar o total de informações, bem como para que a empresa possa apontar os melhores serviços que o cliente estava à procura.

Acredita-se que com a entrada dos leads em qualquer organização, os gestores têm uma visão maior dos seus clientes e conseguem, na maioria das vezes, disponibilizar os produtos ou serviços desejados por eles. Existem vários tipos que permitem a obtenção de dados: a partir de contato telefônico, e-mails, até mesmo em eventos. Após o armazenamento dos referidos dados e da análise de cada um, é feita a separação desses dados, sendo que, em muitas das vezes, essa separação, para render melhores resultados, se dá por nichos e setores, sendo que cada um fica responsável por reter e fidelizar os clientes por meio de ofertas totalmente tentadoras, ocasionando uma demanda e lucros para a empresa, tornando-a maior em seu mercado.

\subsection{PLATAFORMAS}

As plataformas digitais são modelos de negócios que usam a tecnologia com o objetivo de conectar os clientes com os fornecedores para que haja uma conexão entre eles. Com isso, analisaram que, com estas plataformas, agrega-se valor dentro da organização, pois é com elas que conseguimos interagir com os clientes e com os fornecedores com facilidade. Segundo Almeida (2013), a tecnologia está mudando o formato de fazer negócio no território brasileiro, então, tem posto à disposição das organizações um novo modelo para divulgação de seus produtos e marcas. Com a ajuda das plataformas digitais, as organizações têm maiores chances de compreender o perfil de cada cliente, bem como de terem uma boa interação com eles, podendo, também, alcançar segmentos novos a partir de campanhas eficazes, desde que haja rapidez e eficiência.

RC: 100851

Disponível em: https://www.nucleodoconhecimento.com.br/administracao/introducaodo-inbound 
De acordo com Parker, Alstyne e Choudary (2019), pode-se mencionar que, dentre outros fatores que aumentam o desempenho da empresa, o objetivo inicial de uma plataforma é impulsionar e aprimorar, de maneira gradativa e constante, a relação entre os clientes, favorecendo, nesse processo, a troca de bens e serviços, fazendose com que haja maior visibilidade, o que otimiza a criação de valor entre todos os seus usuários. As plataformas digitais são de extrema necessidade para o cotidiano da empresa, pois é ela que facilita a relação de internautas com os fornecedores, fazendo com que haja interações positivas entre os envolvidos. Elas operam a partir de um agrupamento de subsistemas e interfaces que, em conjunto, formam uma estrutura básica a partir da qual as organizações podem efetivar, desenvolver e produzir um amplo subsistema, melhorando as suas performances.

\subsection{TECNOLOGIA DA INFORMAÇÃO - TI}

A Tecnologia da Informação é uma área que utiliza a computação para produzir, transmitir e empregar diversas informações. Sendo assim, a T.I. é um conjunto que envolve todas as atividades e as soluções provenientes de computação. São todos os tipos de tecnologia que cercam a computação e a eletrônica que integram esse universo. Segundo Neto (2019), a Tecnologia da Informação é fundamental para aprimorar o hardware, software e redes. Sendo assim, tem transformado toda a comunidade e a economia global, fazendo-se com que haja uma verdadeira mudança no mundo digital, bem como nos respectivos negócios.

Para Joia et al. (2012), a sociedade contemporânea, altamente globalizada, tem apontado para o alto impacto da Tecnologia da Informação, uma vez que esta pode levar as organizações a terem muitos benefícios competitivos, visto que melhora-se o funcionamento da empresa. Com isso, a Tecnologia da Informação dentro da empresa tem melhorado os seus softwares a partir de um tipo de curso que é oferecido por intermédio da própria corporação. Os resultados e benefícios têm sido nítidos e favoráveis. Sendo assim, como conclusão, observa-se que os softwares têm sido aperfeiçoados e, consequentemente, têm gerado resultados positivos para a organização.

RC: 100851

Disponível em: https://www.nucleodoconhecimento.com.br/administracao/introducaodo-inbound 


\subsection{JORNADA DE COMPRAS}

A jornada de compra é uma via percorrida pelo cliente almejado pela empresa antes da tomada de decisão pela compra. Ela surge por meio de alguns procedimentos, sendo eles a análise, levantamentos e pesquisas de mercado e de consumidores. $\mathrm{O}$ objetivo é o de identificar os pontos que devem ser melhorados para que a empresa atue de forma objetiva, considerando os aspectos que exercem influência direta em seu desempenho. De acordo com Canfield, Gallon e Corte (2017), as organizações veem a jornada de compra como um instrumento que permite mapear todos os pontos significativos da comunicação entre cliente e a corporação a partir do momento em que o comprador se empenha com a marca. Os autores consideram este como um método para obter inovação e evolução no trato do consumidor pelas empresas.

Segundo Camacho (2019), a fim de que seja possível atrair o comprador, é preciso que este já seja um possível lead, um eventual cliente. A jornada de compra apresenta oportunidades para que a empresa tenha um envolvimento com os leads, isto é, para obter bons resultados. A jornada de compra é uma das etapas mais importantes inerente ao relacionamento entre cliente e empresa. Quando essa etapa é bem realizada, a empresa gera o desejo de compra no cliente, mesmo sem a necessidade do mesmo em fazer uma compra naquele momento, além de fidelizar o cliente e conseguir um marketing orgânico, pois ele ficará tão satisfeito com a compra que contará para outras pessoas e também voltará para comprar quando necessitar de um novo produto. Acredita-se que a jornada de compra é benéfica para o cliente e funcionários.

\section{MATERIAIS E MÉTODOS}

De acordo com Meireles (2016), declara-se que a metodologia ajuda a direcionar o discente no emprego do método da pesquisa. O conhecimento adquirido permite que o pesquisador possa investigar e refletir sobre a realidade. Materiais e métodos correspondem a um campo detalhado. É fundamental nesta pesquisa que conta com 
dados científicos, agregar, no estudo de campo, tais dados, pois permite que haja um aprofundamento do tema que perpassa por todo o estudo realizado. Com isso, realizou-se um processo de coleta e análise de informações para o aperfeiçoamento no trabalho, baseando-se na metodologia escolhida. Sendo assim, o trabalho realizado contará com diversos tipos de métodos propostos e ferramentas que ajudam a identificar e a solucionar o desafio posto. A partir disso, demonstrará os pontos a serem melhorados nesta pesquisa de campo.

\subsection{PROCEDIMENTOS METODOLÓGICOS}

O procedimento metodológico com base no método científico tem a finalidade de orientar, conduzir e determinar partes indispensáveis para obter o resultado da pesquisa. Com isso, expôs-se como o cientista pode validar as ações relacionadas às melhorias. Elas serão implantadas tendo como base o resultado obtido a partir da pesquisa de dados realizada junto à empresa $\mathrm{K}$ Maia de Souza, com o objetivo de atrair os clientes e agregar valor à organização, aumentando o seu desempenho. Segundo Aragão e Neta (2017), os procedimentos e técnicas estão de modo direto interligados com o problema de pesquisa e com o alcance dos objetivos exclusivos que fundamentarão as análises e observações alcançadas na pesquisa.

\subsubsection{QUANTO À NATUREZA}

Para Knechtel (2014), declara-se que a pesquisa científica, de forma geral, não é algo simples, pois não é um mero trabalho escolar, mas sim uma investigação científica que tem o objetivo de produzir conhecimentos por meio de atividades intelectuais, sendo elas intencionais e sistemáticas, buscando sempre soluções para necessidades do ser humano. Esta pesquisa é de natureza aplicada e qualitativa. De natureza aplicada porque as ferramentas e processos podem ser utilizados para a organização do estudo, trazendo bons resultados, o que faz com que haja uma aplicação simples e instantânea. A pesquisa parte da natureza qualitativa porque tem como base a coleta de dados a partir de questionários que verificam os itens observados pela pesquisa.

RC: 100851

Disponível em: https://www.nucleodoconhecimento.com.br/administracao/introducaodo-inbound 


\subsubsection{QUANTO AOS FINS}

De acordo com Vergara (2016), recordar-se que a ciência está sempre em busca de oferecer explicações acerca dos fenômenos que no fim são discutíveis é fundamental. Para Carvalho (2019), pesquisas com fins explicativos são chamadas de ciências naturais, cujos critérios de seleção de variáveis e análise dos dados são bastante frágeis e precisam de mais cuidado. A pesquisa se baseia na atividade da investigação, ou seja, caracteriza-se como exploratória, cujo objetivo é o de detectar melhorias para a empresa e apresentar propostas com novas ideologias para monitorar e realizar os serviços com mais rapidez e eficiência. A pesquisa é explicativa, também, porque tem como finalidade identificar os fatores relacionados à causa do problema, bem como visa-se chegar às respostas para a solução dos problemas.

\subsubsection{QUANTO AOS MEIOS}

Para Vergara (2016), não podemos nos esquecer de relacionar os objetivos do projeto aos meios para alcançá-los, bem como adequar à justificativa que alicerça a proposta de pesquisa. De acordo com Zanella (2013), existem dois tipos de estruturas associadas aos meios, as estruturadas e as não estruturadas. Em relação aos meios, afirma-se que as pesquisas de campo se dão por meio de observações no ambiente, coleta de dados na empresa e análises de desempenhos, tendo-se o objetivo de agrupar todas as informações que serão tomadas como base para construir a proposta final da empresa.

\subsection{CARACTERÍSTICAS DA EMPRESA}

A K Maia de Souza Eireli é uma instituição que atua no ramo de assessoria contábil. Oferece aos seus clientes diversos serviços, como fechamento anual, declaração de imposto de renda, assessoria, dentre outros. Foi fundada em 2018 e todos os anos busca pelo melhor desempenho em seu ramo, mantendo-se até hoje no mercado. Sua localização, atualmente, é situada na cidade de Manaus - AM, Rua Brasília, 
307, Bairro São Jorge, CEP 69033-020. Conta com 3 funcionários com os mesmos pensamentos: "ajudar de maneira fácil e prática a vida do cliente". Alia esta ideologia à lógica do mercado atual, tornando-se referência em seu ramo. A K Maia de Souza busca o seu crescimento, pois almeja ocupar os lugares de seus concorrentes e se tornar a melhor no mercado. Para isso, deixa claro ao seu cliente quais são os objetivos e ambições.

\section{RESULTADOS E DISCUSSÕES}

Com base no estudo de caso realizado junto à K Maia de Souza Assessoria Contábil, foi comprovado que a organização tem um desempenho positivo nas áreas funcionais e verificou-se que Marketing é tida como a área mais crítica, de acordo com o gráfico 01 e quadro 01 , em que apresentam-se as ações interventivas para aperfeiçoamentos do plano proposto. Vislumbrou-se, então, que, por meio da coleta de informações, os resultados apontam para esses pontos negativos e positivos em termos de desempenho em áreas distintas. A partir dos resultados do estudo relacionado à etapa do Diagnóstico Organizacional, apresenta-se, a seguir, o resultado que destaca a área de Marketing como a mais crítica, conforme identificase no gráfico 01: Medição de desempenho. 
Gráfico 01: Medição de desempenho

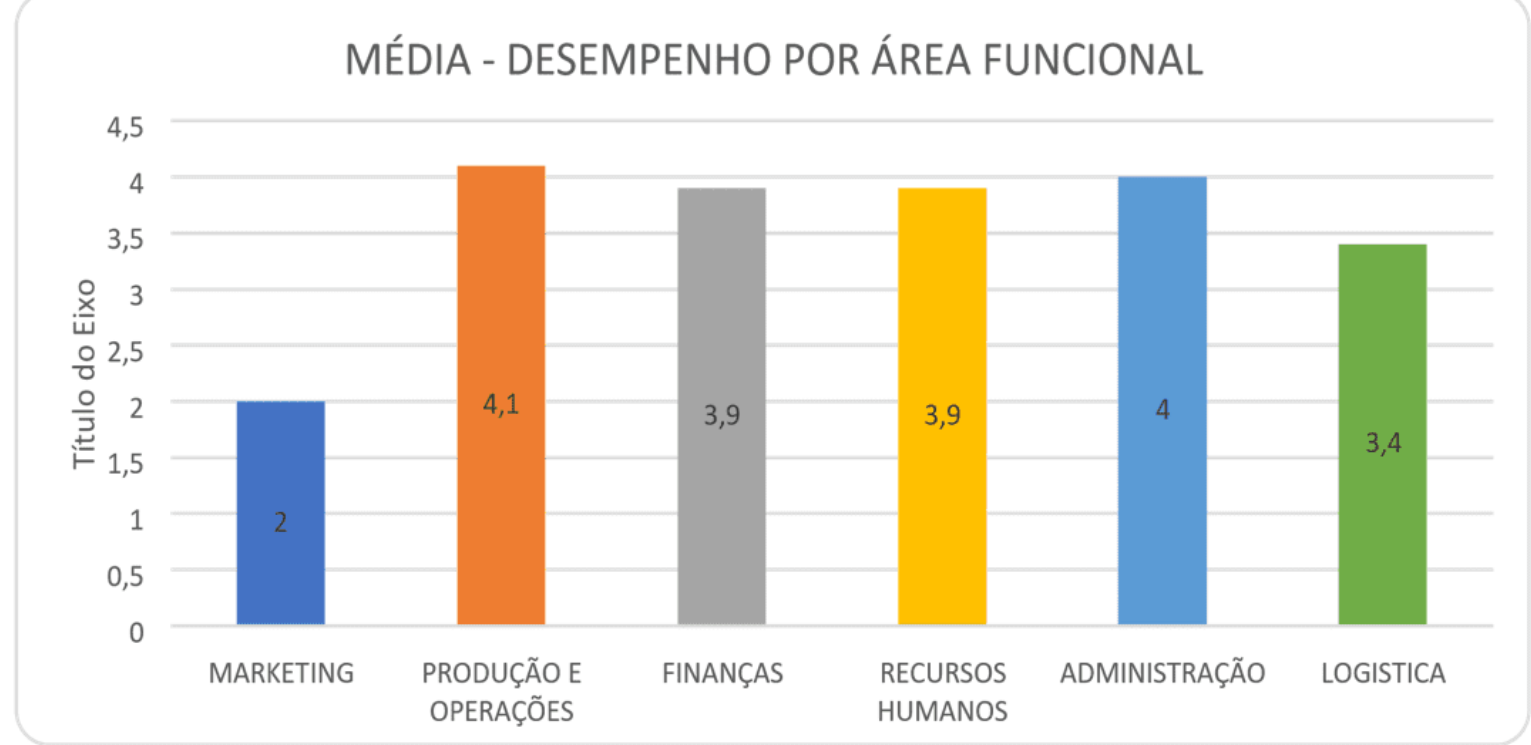

Fonte: Elaboradores pelos autores com base na coleta de dados, 2021.

Conforme demonstrado a partir do gráfico 01, a empresa tem a área das produções e operações como as de melhor desempenho; as áreas de finanças, administração e logística são áreas de desempenho médio. Com isso, a área de Marketing é considerada a mais crítica. É notável que os resultados de Marketing são insatisfatórios. Nesse sentido, recomenda-se, com este estudo, que a organização busque por melhorias de maneira contínua para que, dessa forma, possa fomentar uma mudança nesta área. Com base nisto, o quadro 01 revela alguns desses fatores críticos.

Quadro 01: Marketing

\begin{tabular}{|c|c|c|c|c|c|}
\hline ÁREA FUNCIONAL & \multirow[b]{2}{*}{$\begin{array}{l}\text { Ponto } \\
\text { muito } \\
\text { forte } \\
5\end{array}$} & \multicolumn{2}{|c|}{$\begin{array}{l}\text { NÍVEL OU } \\
\text { AVALIAÇÃO }\end{array}$} & \multicolumn{2}{|c|}{ GRAU DE } \\
\hline MARKETING & & $\begin{array}{l}\text { Ponto } \\
\text { forte } \\
4\end{array}$ & $\begin{array}{l}\text { Ponto } \\
\text { médio } \\
3\end{array}$ & $\begin{array}{l}\text { Ponto } \\
\text { fraco } \\
2\end{array}$ & $\begin{array}{l}\text { Ponto } \\
\text { muito } \\
\text { fraco } \\
1\end{array}$ \\
\hline Utiliza-se redes sociais na empresa & & & & $x$ & \\
\hline
\end{tabular}

RC: 100851

Disponível em: https://www.nucleodoconhecimento.com.br/administracao/introducaodo-inbound 


\begin{tabular}{|c|c|c|c|c|c|c|}
\hline 2 & $\begin{array}{l}\text { Investe-se em algum gestor de } \\
\text { tráfego }\end{array}$ & & & & & $x$ \\
\hline 3 & $\begin{array}{l}\text { Além das redes sociais, possui outro } \\
\text { meio de comunicação }\end{array}$ & & & & $x$ & \\
\hline 4 & $\begin{array}{l}\text { Apresentam-se mais demandas } \\
\text { através do marketing }\end{array}$ & & & & $x$ & \\
\hline 5 & A empresa investe em pós-vendas & & & $x$ & & \\
\hline 6 & $\begin{array}{l}\text { Os clientes deixam feedback para a } \\
\text { empresa }\end{array}$ & & & $x$ & & \\
\hline 7 & $\begin{array}{l}\text { Propôs-se uma equipe apenas para } \\
\text { cuidar do marketing digital }\end{array}$ & & & & & $x$ \\
\hline 8 & $\begin{array}{l}\text { As redes sociais trouxeram algum } \\
\text { benefício para empresa }\end{array}$ & & & & $x$ & \\
\hline 9 & $\begin{array}{l}\text { Constata-se um contato direto com o } \\
\text { cliente }\end{array}$ & & & $x$ & & \\
\hline 10 & $\begin{array}{l}\text { A empresa possui um bom alcance } \\
\text { através das redes sociais }\end{array}$ & & & & & $x$ \\
\hline \multicolumn{2}{|c|}{ TOTAL $(\Sigma)$} & 0 & 0 & 9 & 8 & 3 \\
\hline \multicolumn{2}{|r|}{ MÉDIA POR GRAU (POR COLUNA) } & 0 & 0 & 0,9 & 0,8 & 0,3 \\
\hline \multicolumn{2}{|c|}{ DESEMPENHO DA ÁREA $(\Sigma)$ TOTAL } & & 2 & & & \\
\hline
\end{tabular}

Fonte: Elaborado pelos autores com base na coleta de dados, 2021

Diante do quadro 01 apresentado, observou-se que a área de marketing não possui pontos fortes, somente pontos médios e fracos nesta organização, demonstrando, dessa forma, a necessidade de apresentar possíveis soluções para os problemas encontrados. Deste modo, o problema da pesquisa consiste em avaliar a seguinte questão: Como a introdução do inbound marketing pode beneficiar as microempresas? 


\subsection{PLANEJAMENTOS DE AÇÕES}

Um plano de ação é uma forma ordenada e que acompanha certo método determinado. A partir da definição das metas e propósitos, as tarefas que devem ser realizadas. Aponta-se, também, os responsáveis pelo crescimento do negócio, sendo que eles devem conduzir todo o andamento de um projeto que tem como intuito a melhora do desempenho. Tais cuidados são necessários para que se possa atingir os objetivos propostos pela organização.

Quadro 02: Ações interventivas

\begin{tabular}{|l|l|l|l|l|}
\hline $\mathbf{0 1}$ & Ações Interventivas & $\begin{array}{l}\text { Cronologia } \\
\text { Acompanhar os resultados da } \\
\text { empresa }\end{array}$ & $\begin{array}{l}\text { Duração } \\
\text { Setembro/2021 }\end{array}$ & $\begin{array}{l}\text { Custo dias } \\
\mathrm{R} \$\end{array}$ \\
\hline $\mathbf{0 2}$ & $\begin{array}{l}\text { Estruturar os leads após a capitação } \\
1500,00\end{array}$ & Outubro/2021 & 30 dias & $\begin{array}{l}\mathrm{R} \$ \\
2500,00\end{array}$ \\
$\mathbf{0 3}$ & $\begin{array}{l}\text { Moldar as plataformas para rápidas } \\
\text { buscas }\end{array}$ & Novembro/2021 & 30 dias & $\mathrm{R} \$$ \\
\hline $\mathbf{0 4}$ & $\begin{array}{l}\text { Formação de T.I na empresa para } \\
\text { melhoria do software }\end{array}$ & Dezembro/2021 & 30 dias & $\begin{array}{l}\mathrm{R} \$ \\
5000,00\end{array}$ \\
\hline $\mathbf{0 5}$ & $\begin{array}{l}\text { Priorizar as jornadas de compra. } \\
5000,00\end{array}$ \\
\hline
\end{tabular}

Fonte: Elaborado pelos autores, 2021

A proposta de solução para cada etapa desenvolveu-se por meio da ferramenta $5 \mathrm{w} 2 \mathrm{~h}$, que é um conjunto composto por certas questões utilizado para elaborar planos de ação de maneira veloz e eficiente. O seu principal objetivo é a definição de exercícios eficazes, assim como visa orientar os gestores de maneira visual, ágil e compreensível. De acordo com Custodio (2015), a ferramenta 5w2h foca em um plano de ação organizado e claro que envia a solução dos problemas de forma fácil 
para que haja a tomada de ações, visando-se, com isso, identificar os principais componentes a serem abordados.

\subsubsection{ACOMPANHAR OS RESULTADOS DA EMPRESA}

O acompanhamento dos resultados da empresa faz-se necessário em qualquer organização. Destaca-se que os gestores da empresa precisam monitorar os seus colaboradores para o possível acompanhamento das atividades e dos seus serviços. Busca-se por meio dos resultados uma melhoria eficaz na produtividade da empresa, bem como uma maior agilidade na entrega das demandas solicitadas. Após as metas estabelecidas, a empresa tem uma tendência de melhoria.

Quadro 03: 5w2h - Acompanhar os resultados da empresa

Acompanhar os resultados da empresa

O que? Acompanhar o resultado da empresa.

Por quê? Buscando-se a eficácia nas atividades e serviços.

Onde? Assessoria Contábil K Maia de Souza Eireli.

Quando? Segunda semana de setembro de 2021.

Quem? Gestão da empresa.

Como? Através da contratação de um analista de desenvolvimento, para avaliar os resultados dos serviços e a demanda de tempo.

Quanto? $\mathrm{R} \$ 1.500,00$

Fonte: Elaborado pelos autores, 2021

Observou-se que o acompanhamento dos resultados na organização, a partir do comprometimento de um analista de desenvolvimento, fez com que a empresa estabelecesse uma estrutura de demanda de tempo, fornecendo serviços melhores. Sendo assim destaca-se um bom desempenho por parte dos colaboradores da organização. Acredita-se que após a implementação, os resultados serão satisfatórios, pois os colaboradores adotarão uma melhor estratégia para 
pesquisarem e facilitarem os seus serviços e atividades determinados pelos seus gestores.

\subsubsection{ESTRUTURAR OS LEADS APÓS A CAPACITAÇÃO}

Destaca-se que os leads das empresas são essenciais para os colaboradores e gestores da empresa. A partir deles, os contatos dos possíveis consumidores estarão dispostos à organização. É um mecanismo para chamar atenção dos clientes, tornando mais atraentes os serviços a eles prestados, sendo que esses devem se encaixar no tipo de perfil dos consumidores que têm potencial de interesse nesses produtos específicos.

Quadro 03: 5w2h - Estruturar os leads após a capitação

\begin{tabular}{|l|l|}
\hline & Estruturar os leads após a capitação \\
\hline O que? & Estruturar os leads após a captação. \\
\hline Por quê? & Melhorar a relação do cliente com a empresa. \\
\hline Onde? & Assessoria contábil K Maia de Souza Eireli. \\
\hline Quando? & Primeira semana de Outubro de 2021. \\
\hline Quem? & Departamento de T.I. \\
\hline Como? & Através da criação de um sistema que possa levar o cliente com fácil \\
& acesso para o site e interagir. \\
\hline Quanto? & $R \$ 2.500,00$ \\
\hline
\end{tabular}

Fonte: Elaborado pelos autores, 2021

Estruturam-se os leads após a capacitação, com o intuito de levar os clientes a um fácil acesso aos sites, de modo que possam interagir com facilidade dentro deste meio. Destacou-se uma melhoria dentro desta área de atuação após a criação do sistema. Apresentou-se um resultado positivo por meio deste sistema, pois gerou-se uma interação maior com os clientes, fomentando-se, portanto, novos meios de 
comunicação e nichos que os clientes estavam procurando, uma vez que a plataforma interativa tem este objetivo.

\subsubsection{MOLDAR AS PLATAFORMAS PARA BUSCAS RÁPIDAS}

Estabeleceu-se a busca contínua pela melhora da empresa, com intuito de torná-la mais sofisticada. Todavia, foi necessário o investimento nas tecnologias que operam em todo o mercado e em qualquer nicho. Por este motivo, a organização precisou adotar certos moldes em toda sua plataforma digital e física para que pudesse sempre estar um passo à frente em relação ao seu concorrente. Foi necessária a colaboração de toda equipe, sendo que todos precisam entender a nova metodologia da empresa para que isso não se tornasse um empecilho para os colaboradores, nem para os clientes.

Quadro 04: 5w2h - Moldar as plataformas para rápidas buscas

\begin{tabular}{|l|l|}
\hline O que? & Moldar as plataformas para rápidas buscas \\
\hline Por quê? & Trazer mais eficiência para a navegação do cliente. \\
\hline Onde? & Assessoria contábil K Maia de Souza Eireli. \\
\hline Quando? & Primeira semana de Novembro de 2021. \\
\hline Quem? & Departamento de T.I. \\
\hline Como? & Através de atualizações no site da empresa. \\
\hline Quanto? & $\mathrm{R} \$ 3.000,00$ \\
\hline
\end{tabular}

Fonte: Elaborado pelos autores, 2021

Para isso, adotou-se um método que fomentou as melhorias que fez com que a plataforma de interação e buscas rápidas fossem mais ágeis, fornecendo, de maneira constante, atualizações dentro do site da empresa. Essas atualizações fizeram com que o site facilitasse 0 acesso para que os clientes navegassem de forma mais rápida dentro desta plataforma. Avaliou-se que após as atualizações nas 
plataformas o andamento dos serviços rendeu mais do que esperado e, assim, a empresa teve um feedback melhor por fornecer uma resposta mais rápida para os serviços solicitados pelos clientes e por ter ganhado mais tempo para produzir os seus próprios serviços.

\subsubsection{FORMAÇÃO DE T.I. NA EMPRESA PARA A MELHORA DE SOFTWARES}

A organização precisa investir na área de Tecnologia da Informação para que alcance o resultado que almeja nas suas atividades e serviços. A partir da formação de um departamento especializado na área de informação, qualquer tipo de problema será resolvido e a empresa não lidará de maneira frequente com as surpresas inesperadas ligadas ao mercado que atua.

Quadro 05: 5w2h - Formação de T.I. na empresa para melhora do software

\begin{tabular}{|l|l|}
\hline & Formação de T.I. na empresa para melhora do software \\
\hline O que? & Formação de T.I. na empresa para melhora do software \\
\hline Por quê? & Ter um departamento especializado em T.I. \\
\hline Onde? & Assessoria contábil K Maia de Souza Eireli. \\
\hline Quando? & Terceira semana de Dezembro de 2021. \\
\hline Quem? & Gestores \\
\hline Como? & Através de cursos profissionalizantes. \\
\hline Quanto? & R $\$ 5.000,00$ \\
\hline
\end{tabular}

Fonte: Elaborado pelos autores, 2021

Os cursos profissionalizantes da área de $\mathrm{Tl}$ fizeram com que os funcionários da organização agregassem valor às atividades da empresa no dia a dia organizacional, pois passaram a produzir de maneira mais efetiva, tornando a empresa mais competitiva no nicho no qual atua. Isto fez que a corporação tivesse pessoas capacitadas nessa área, o que permitiu a obtenção de excelentes 
resultados, apresentando-se, consequentemente, em virtude de tal qualificação, diversas soluções para os softwares. Entende-se que, após a criação do departamento de T.I, a empresa ficou menos dependente das antigas maneiras de comandar os seus serviços, pois, com a criação de programas e softwares, todas as maneiras de monitorar a empresa foram sofisticadas, de modo que passou a atender aos requisitos necessários para o mercado.

\subsubsection{PRIORIZAR A JORNADA DE COMPRAS}

Como qualquer ramo, não importa qual seja, os clientes buscam produtos que os agradem de alguma forma, estejam eles precisando ou não. É por meio da jornada de compra que a empresa irá monitorar a busca pelo produto que o seu cliente almeja. Com isso, o departamento responsável conseguirá produzir e entregar conteúdos relacionados aos desejos do seu cliente.

Quadro 06: 5w2h - Priorizar a jornada de compras

\begin{tabular}{|l|l|}
\hline O que? & Priorizar a jornada de compras \\
\hline Por quê? & Levar o cliente ao seu produto específico. \\
\hline Onde? & Assessoria contábil K Maia de Souza Eireli. \\
\hline Quando? & Terceira semana de Janeiro de 2022. \\
\hline Quem? & Gestores \\
\hline Como? & Através de cursos profissionalizantes. \\
\hline Quanto? & $\mathrm{R} \$ 500,00$ \\
\hline
\end{tabular}

Fonte: Elaborado pelos autores, 2021

A importância da priorização da jornada de compras se dá pela sua contribuição relacionada ao aprimoramento da performance diária do negócio, pois todo o cliente percorre um caminho antes de se tornar um cliente fidelizado. Sendo assim, constatou-se que o curso profissionalizante agregaria valor para a corporação, pois 
conduziria o cliente a maior satisfação ao consumir os produtos e/ou serviços da empresa em diferentes momentos. Considerou-se que após a empresa entender o mecanismo da jornada de compras, percebendo quais os serviços e produtos que os seus clientes estavam atrás, a demanda da contratação dos mesmos foi maior, tornando a empresa mais lucrativa, apontando-se para um resultado positivo para a mesma.

\section{CONSIDERAÇÕES FINAIS}

Conclui-se que os resultados observados por meio da pesquisa de campo trouxeram para a empresa novos aspectos. Ela se tornou mais competitiva e ganhou maior visibilidade no mercado onde atua, pois, a partir do momento em que empregou os métodos indicados por esta pesquisa, os resultados foram satisfatórios. Por ser uma empresa de pequeno porte e ter várias limitações, os quadros de soluções feitos tiveram que ser estudados e aplicados de maneira que não comprometessem o orçamento da empresa e os seus futuros gastos. Após as implementações das ações diretas na empresa, observou-se que existiam áreas a serem melhoradas ainda. Todavia, houve um grande avanço na empresa e, assim, pôde alavancar a oferta e venda dos seus produtos e serviços. Os resultados que a pesquisa proporcionou para a organização foram positivos, pois esta se tornou eficaz e produtiva, bem como deixou os colaboradores e clientes satisfeitos.

Destacou-se que após as ideias criadas para ajudar a empresa a obter resultados positivos e alavancar os seus negócios, os objetivos, na prática, revelaram-se como complexos por conta da necessidade de adaptação e da nova forma de se relacionar com as ideias e projetos sustentados pela pesquisa em campo, então, houve algumas desavenças e estresses do dia a dia que acabaram atrasando um pouco a chegada ao resultado final. Contudo, o inbound marketing entende que a melhor maneira de ganhar o cliente é por meio da tecnologia usada no nosso dia a dia. A pergunta problema: Como a introdução do Inbound Marketing pode beneficiar as microempresas? foi respondida. A introdução do Inbound marketing beneficia a organização no sentido de disponibilizar conteúdos que atraem clientes, produzem

RC: 100851

Disponível em: https://www.nucleodoconhecimento.com.br/administracao/introducaodo-inbound 
resultados mais assertivos, otimizam os gastos com comunicação e estratégias de marketing e melhoram o ranqueamento das microempresas em buscas orgânicas e, por fim, geram vendas qualificadas e maior retorno de investimento

Conclui-se, após todas as pesquisas feitas e as propostas construídas, que o resultado final do estudo proporcionou sentimento de dever cumprido, visto que os objetivos do estudo foram atingidos e proporcionaram um legado teórico para futuras pesquisas e, além de beneficiar os acadêmicos, ajudou, também, a empresa estudada a permanecer intacta no nicho que atua. A pesquisa também serve como base para futuros estudos sobre o tema.

\section{REFERÊNCIAS}

ALMEIDA, M. Mundo digital: como esse poderoso canal pode ajudar no sucesso de seu negócio. São Paulo, 2013. Disponível em: https://gestaofitness.com.br/mundo-digital-como-esse-poderoso-canal-pode-ajudarno-sucesso-de-seu-negocio/. Acesso em: 04 nov. 2021.

ARAGÃO, J. W. M.; NETA, M. A. H. M. Metodologia científica. Salvador: UFBA, 2017.

CALIL, A. Inbound Marketing: estratégias práticas para empresas e projetos. São Paulo: Ed. Casa do Código, 2019.

CAMACHO, D. Marketing digital: Compra de mídia e Inbound. São Paulo: Ed. Senac, 2019.

CANFIELD, D. de. S.; GALLON, S.; CORTE, V. F. D. O Design Thinking na Jornada do Consumidor em uma Steakhouse no Brasil. Revista Caderno Profissional de Marketing - Unimep, Piracicaba, v. 5, n. 3, p.1-14, dez. 2017. 
CARVALHO, L. O. R Metodologia científica; Teoria e aplicação na educação a distância. Petrolina, PE: Universidade Federal do Vale do Rio São Francisco, 2019.

CONVERSION, T. A complete guide to lead generation. 2015.

FRANCISCHINI, P. G. Indicadores de desempenho: dos objetivos à ação métodos para elaborar KPIs e obter resultados. Rio de Janeiro: Ed. Alta Books, 2017.

GROVE, A. S. Gestão de Alta Performance - tudo o que um gestor precisa saber para gerenciar equipes e manter o foco em resultados. São Paulo: Ed. Saraiva, 2020.

GUIMARÃES, V. Inbound Marketing: 10 Dicas Valiosas para Atrair o Seu Público Usando ímãs Virtuais. Ed. Independently Published, 2018.

JOIA, L. et al. Gestão estratégica da tecnologia da informação. Rio de Janeiro: Editora da FGV, 2012.

KNECHTEL, M. do. R. Metodologia da pesquisa em educação: uma abordagem teórica-prática dialogada. Curitiba: Intersaberes, 2014.

LIMA, V. M. do. R. Métodos de análise em pesquisa qualitativa. Porto Alegre: Ed. Edipucrs, 2019.

MEIRELES, L. Metodologia do estudo e pesquisa. Rio de Janeiro: Ed. Vozes, 2016.

NETO, M. Gestão da tecnologia da informação. Rio de Janeiro: Editora Brasport, 2019.

PARKER, G.; ALSTYNE, M. V.; CHOUDARY, S. P. Plataforma: a revolução da estratégia. Rio de Janeiro: Alta Books, 2019. 
SILVA, R. P.; GALEGAGE, N. V. Processo de sales lead sharing utilizando CRM (customer relationship management) integrado com ERP (enterprise resource planning) apoiando o planejamento da demanda. In: XIII workshop de pósgraduação e pesquisa do Centro Paula Souza, São Paulo, 2018.

VERGARA, S. C. Projetos e relatórios de pesquisa em administração. $16^{\underline{a}}$ ed. São Paulo: Atlas 2016.

ZANELLA, L. C. H. Metodologia de pesquisa. $2^{\mathrm{a}}$ ed. Florianópolis: UFSC, 2013.

Enviado: Outubro, 2021.

Aprovado: Novembro, 2021. 